\title{
Application of the optimally alloyed cast irons in order to increase the durability and to ensure the cost reduction of mining and metallurgical products
}

\author{
Dmitry Lubyanoi ${ }^{1 *}$, Evgeny Pudov ${ }^{1}$, Evgeny Kuzin $^{1}$, and Olga Semenova ${ }^{1}$ \\ ${ }^{1}$ T.F. Gorbachev Kuzbass State Technical University, Branch of Prokopievsk 653039, 19a \\ Nogradskaya str., Prokopievsk, Kemerovo region, Russian Federation
}

\begin{abstract}
The article shows the relevance of the use of alloyed cast iron in mining and metallurgical engineering. The article discusses the technologies for producing naturally alloyed cast iron. For working bodies and friction units of mining machines, such as pumps, coal pumps, hydrocyclones, crushers and mills. The main type of wear for them is abrasive. To increase the wear resistance of cast iron the production of cast iron has not been sufficiently studied yet. Although the use of cast iron in a complex alloyed with manganese, silicon, chromium, titanium and vanadium has been studied. The article studies the influence of manganese, titanium and vanadium on the mechanical properties and performance of machine parts and products of mining and metallurgical production in contact with hightemperature and highly abrasive media. The rational content of titanium and vanadium in gray cast irons is established in the range of $0.05-0.1 \%$, which ensures their heat resistance and increases their wear resistance. The content of these elements can be increased to $0.07-0.12 \%$. Bushings made of this cast iron have the required wear resistance and can increase the operational reliability of the equipment in the conditions of mining and metallurgical production. They also replace non-ferrous metals, as well as products obtained by powder metallurgy methods.
\end{abstract}

\section{Introduction}

Improving the performance of machine parts of mining and metallurgical equipment is the most important task of mining and metallurgical engineering. The insufficient service life of these products significantly reduces the economic efficiency of the technologies used. It leads to high metal consumption of equipment used in mining and metallurgical production.

\footnotetext{
* Corresponding author: Lubjanoy@yandex.ru
} 


\section{Formulation of the problem}

To make optimal technology for producing cast irons with the necessary properties it is necessary to develop a low-cost technology for their production. It also should determine the optimal content of alloying elements in each specific product or group of products. As it has been previously noted, vanadium can significantly reduce the manganese content in heat-resistant and wear-resistant cast irons. One of the most important tasks is to determine the acceptable concentration of manganese in cast iron with an optimal content of silicon, titanium and vanadium. As noted in [1], it is important to ensure long service life of parts in the mining, coal and metallurgical industries and other industries associated with the processing of highly abrasive raw materials (metallurgical slag, ore, sludge, rocks). Such products and devices include mills, intermediate bucket covers, pumps, bushings, coal pumps, centrifuges, armors, hydro cyclones, slag bowls, coal and ore - grinding mills. During the manufacture of these products they are used as various types of white cast iron, which have high wear resistance (5-10 times higher than structural steels) [1], and optimally-alloyed gray cast irons. The later have the maximum operational resistance in the production of replaceable metallurgical equipment (slag pits, intermediate bucket covers, mills) [2]. The chemical composition of the cast iron, the technology of melting the cast iron, the technology of manufacturing products, the number and size of carbides [1] determine the properties of the white cast irons. In [1], the influence of carbon, chromium, molybdenum, and phosphorus on the mechanical properties and workability of white cast irons is emphasized. The influence of titanium and vanadium is not sufficiently studied as both in the studies of the properties of white cast irons and optimally alloyed gray structural and heat-resistant cast irons [2-4].

\section{Research result}

In the conditions of EVRAZ ZSMK JSC, studies were conducted to assess the effect of doping with silicon, manganese, titanium and vanadium of gray cast iron [4-6]. Studies have shown an increase in the tensile strength of cast iron. These dependencies are described by the equations:

$$
\begin{aligned}
& \sigma=-3.71+291.7 \mathrm{~V} \\
& \sigma=-5.00+325.0 \mathrm{Ti} .
\end{aligned}
$$

where $\sigma$ - is the tensile strength of cast iron, $\mathrm{kg} / \mathrm{mm} 2 ; \mathrm{V}$, Ti is the content of vanadium and titanium elements in cast iron, $\%$, respectively.

As shown by industrial tests, an increase in the strength properties of cast iron leads to a decrease in the erosion of products (mills and pallets) by a falling jet of molten metal. The use of optimal alloying in the conditions of EVRAZ ZSMK JSC increased the heat resistance of the products by $7-12 \%$ [6]. The test results showed that an excessively high content of vanadium and titanium in cast iron leads to a decrease in the fluidity of the metal. It leads to the formation of shells and porosity in castings. To increase the fluidity the cast iron was alloyed with ferrosilicomanganese and ferrophosphorus in a bucket. Industrial tests and crushing of decommissioned products have shown that shrinkage defects and micropores are practically absent in castings doped with phosphorus, due to better filling of molds [7]. This effect was observed when the phosphorus content in heat-resistant cast iron exceeds $0.21 \%$ [8]. 
The main phases of cast iron (titanium carbide, phosphide eutectic, and pearlite matrix) were analyzed by optical microscopy and microstructural analysis [9]. It was found that naturally alloyed cast iron also has all the characteristics necessary to increase the service life of wearresistant and heat-resistant products: high strength and good fluidity. It can be due to the presence of low-melting phosphide eutectic. Naturally alloyed cast iron was used to cast the pump bushings used for pumping liquid oxygen. Made of naturally alloyed cast iron containing chromium $0.04 \%$; both titanium and vanadium by $0.05 \%$. the bushings were cast. They were operated in the conditions of metallurgical production. The tests showed that the wear resistance of the bushings was not inferior to the bushings obtained by powder metallurgy methods, as well as those made of non-ferrous alloys. The cost of manufacturing these bushings is 5-17 times lower than the cost of manufacturing bushings made of nonferrous metals (bronze and brass). Studies were conducted on heat-resistant castings (molds and pallets) to assess the effectiveness of the use of vanadium to increase the heat resistance of products. Statistical models describing the effect of the alloying elements vanadium $V, \%$, manganese $\mathrm{Mn}, \%$ and silicon additives $\mathrm{Si}, \%$ on the number of fillings in the molds $(\mathrm{N})$ are given below:

$$
\begin{array}{r}
N=31,3+22,2 \mathrm{~V}+14,34 \mathrm{Si} \\
N=24,6+8,137 \mathrm{Mn}+12,87 \mathrm{Si}
\end{array}
$$

After analyzing the coefficients for vanadium and manganese (V 22.2 / Mn 8,137 = 2.73) we can conclude that vanadium affects almost three times more strongly the heat resistance of castings than manganese. It should be noted, that titanium and vanadium are introduced into cast iron by agglomerate and pellets used for melting in blast furnaces.

It is also necessary to note that alloying with silicon and manganese during overflow is made in a cast iron bucket. As a result, it is advisable to reduce the addition of manganesecontaining ferroalloys with an increase in the charge of components containing vanadium.

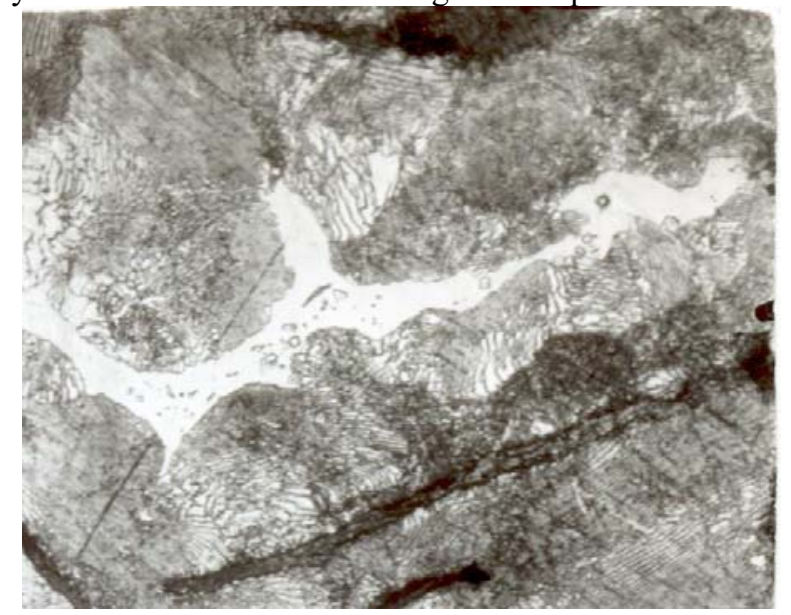

Fig. Large carbonitrides of titanium and vanadium in phosphide eutectic $\mathrm{P}=0.30 \% \times 800$

It was found that both titanium and vanadium liquate into phosphide eutectic. In addition, titanium and vanadium cabonitrides are introduced into phosphide eutectic [9]. All this in combination stabilizes phosphide eutectic and neutralizes the negative effect of phosphorus on the heat resistance of cast iron castings (see figure).

The influence of vanadium and manganese on the stability of blast furnace cast iron mills should be considered together, introducing the concept of manganese equivalent Мnэкв, \%. 


$$
\mathrm{Mn} э \kappa s=\mathrm{Mn}+3 \mathrm{~V}
$$

Statistical processing allowed us to obtain the following regression equation of the effect of the manganese equivalent on the operational stability of the heavy-duty cast iron mills:

$$
N=62,91 \mathrm{Mnэ \kappa в}-25,27 \mathrm{Mnэ \kappa \varepsilon ^{2 }}-3,17
$$

The operational stability of the pallets of the through mills of JSC "ZSMK", obtained from induction smelting cast iron, depending on the manganese equivalent is described by the regression equation:

$$
N=183,61-94,725 \text { Мпэкв }
$$

Based on the obtained dependencies, wear-resistant and heat-resistant cast irons were developed. They are widely used in mining engineering and metallurgy. Products obtained from cast iron alloyed with vanadium and titanium have low production costs characteristics and high technological efficiency in production. These products are widely used in the enterprises of Siberia [9] and the Urals. The works [8-12] consider other methods of increasing the durability and wear resistance of products, for example, out-of-furnace processing of cast iron. It is important to note, that the wear resistance and heat resistance of castings are greatly affected by the thermal treatment of the cast iron melt [2]. The obtained data of this work enable to note that the issue of increasing the wear resistance and operational resistance of products must be approached comprehensively. On the one hand, the properties of the materials of the products and the technology of melt preparation and casting should be taken into account. On the other hand, the optimization of operating modes should be taken into account.

\section{Conclusion}

Thus, the microalloying of cast iron with manganese, titanium and vanadium. significantly increases the strength properties, heat resistance and wear resistance of cast iron. This significantly increases the operational resistance of products operating under conditions of abrasive wear and high temperatures. The optimal content of titanium and vanadium in gray cast iron is found in the range of $0.05-0.12 \%$, which provides the required strength properties of component parts, while increasing their heat resistance and wear resistance. Bushings made of this cast iron have the required wear resistance and allow the increasing the operational reliability of the equipment in the conditions of mining and metallurgical production. Vanadium is also a substitute for manganese in cast iron in blast furnace and induction smelting. It is necessary to reduce significantly the alloying of the metal with manganese in order to save manganese-containing ferroalloys. During the production, only the initial vanadium content in cast iron should be taken into account. These cast irons have found wide application at the enterprises of the Urals and Siberia and at other consumers. 


\section{References}

1. V. Trukhin, A. Trukhin, Investigation of titanium additives on the workability of wearresistant cast iron. Bulletin of the Kuzbass state technical University, 2, 58-60 (2014)

2. D. Lubyanoi, A. Drobyshev, Y. Samsonov, I. Kaminskaya, Higher Efficiency of Manufacturing of Steel Casting Equipment from Pig Iron. Steel Transl., 6, 40-41 (1994)

3. F.I. Azof, L. Kolbeinsen, J. Safarian, Characteristics of Calcium-Aluminate Slags and Pig Iron Produced from Smelting-Reduction of Low-Grade Bauxites. Metall. Mater. Trans. B Process Metall. Mater. Process. Sci, 49, 2400 (2018)

4. H. Berns, B. Wewers, Development of an abrasion resistant steel composite with in situ TiC particles. Wear, 251, 1386-1395 (2001)

5. D. Lubyanoi, A. Sofroshenkov, I. Sinyavskii, E. Makarov, V. Gorkavenko, Technology of neutralizing the harmful effect of phosphorus in iron of heat-resistant castings. Steel Transl., 29, 86 (1999)

6. V. Andreev, D. Lubyanoi, Y. Samsonov, I. Kaminskaya, S. Lubyanaya, Development of Extra-Furnace Treatment Technology for Blast-Furnace Iron in Order to Manufacture Replacement Metallurgical Equipment with Improved Operating Life. Metallurgist, 58, 492 (2014)

7. D. Lubyanoj, I. Sanyasi, I. Selyanin, A.Sofroshenkov, O. Morozova, Influence of conditions of ladle treatment on structure, casting and mechanical properties of phosphorus-containing cast iron produced in blast furnaces. Izv. Ferr. Metall, 53 (2001)

8. D. Lubyanoi, V. Gorkavenko, E. Makarov, I. Kaminskaya,; A. Frolov, N. Yakovenko, Phosphorous cast iron for heat-resistant castings. Met. Sci. Heat Treat, 44, 452 (2004)

9. D. A. Lubyanoy, E. Yu. Pudov,V. Markidonov and A. B. Efremenkov IOP Conf. Series: Materials Science and Engineering, 939, 012045 (2020)

10. B. Gerike, I. Panachev, E. Kuzin, E3S Web of Conferences, 15, 03008 (2017)

11. D. Valeev, D. Zinoveev, A. Kondratiev, D. Lubyanoi, D. Pankratov Reductive smelting of neutralized red mud for iron recovery and produced pig iron for heat-resistant castings Metals 10:1, 32 (2020)

12. E. Kuzin, B. Gerike, Y. Drozdenko et al. IOP Conf. Series: Materials Science and Engineering, 253, 012013 (2017) 